\title{
Feasibility Study of Beta Detector for Small Leak Detection inside the Reactor Containment
}

\author{
JaeYeong Jang, Thomas Schaarschmidt, Yong Kyun Kim* \\ Department of Nuclear Engineering, Hanyang University, Seoul, Korea
}

\section{Technical Paper}

Received October 30, 2018

Revision November 14, 2018

Accepted December 4, 2018

Corresponding author: Yong Kyun Kim

Department of Nuclear Engineering, Hanyang University, 222 Wangsimni-ro,

Seongdong-gu, Seoul 04763, Korea

Tel: +82-2-2220-4450

Fax: +82-2-2296-2354

E-mail:ykkim4@hanyang.ac.kr
Background: To prevent small leakage accidents, a real-time and direct detection system for small leaks with a detection limit below that of existing systems, e.g. $0.5 \mathrm{gpm} \cdot \mathrm{hr}^{-1}$, is required. In this study, a small-size beta detector, which can be installed inside the reactor containment (CT) building and detect small leaks directly, was suggested and its feasibility was evaluated using MCNPX simulation.

Materials and Methods: A target nuclide was selected through analysis of radiation from radionuclides in the reactor coolant system (RCS) and the spectrum was obtained via a silicon detector simulated in MCNPX. A window was designed to reduce the background signal caused by other nuclides. The sensitivity of the detector was also estimated, and its shielding designed for installation inside the reactor CT.

Results and Discussion: The beta and gamma spectrum of the silicon detector showed a negligible gamma signal but it also contained an undesired peak at $0.22 \mathrm{MeV}$ due to other nuclides, not the ${ }^{16} \mathrm{~N}$ target nuclide. Window to remove the peak was derived as $0.4 \mathrm{~mm}$ for beryllium. The sensitivity of silicon beta detector with a beryllium window of $1.7 \mathrm{~mm}$ thickness was derived as $5.172 \times 10^{-6} \mu \mathrm{Ci} \cdot \mathrm{cc}^{-1}$. In addition, the specification of the shielding was evaluated through simulations, and the results showed that the integrity of the silicon detector can be maintained with lead shielding of $3 \mathrm{~cm}(<15 \mathrm{~kg})$. This is a very small amount compared to the specifications of the lead shielding $(600 \mathrm{~kg})$ required for installation of ${ }^{16} \mathrm{~N}$ gamma detector in inside reactor CT, it was determined that beta detector would have a distinct advantage in terms of miniaturization.

Conclusion: The feasibility of the beta detector was evaluated for installation inside the reactor CT to detect small leaks below $0.5 \mathrm{gpm} \cdot \mathrm{hr}^{-1}$. In future, the design will be optimized on specific data.

Keywords: Beta detector, Leakage detection system, ${ }^{16} \mathrm{~N}$, Reactor Coolant System, Unidentified leakage, RCS leakage

This is an Open-Access article distributed under the terms of the Creative Commons Attribution NonCommercial License (http://creativecommons.org/ licenses/by-nc/4.0) which permits unrestricted noncommercial use, distribution, and reproduction in any medium, provided the original work is properly cited.

Copyright $\odot$ 2018 The Korean Association for Radiation Protection

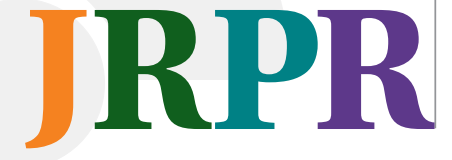

\section{Introduction}

The unidentified leakage detection system of reactor coolant systems (RCS) used in current nuclear power plants is based on indirect measurement methods such as humidity and radioactivity monitoring inside the reactor containment (CT), and sump tank level monitoring. Such a system is able to detect RCS leakages at a rate of 1 gallon per minutes in one hour $\left(1 \mathrm{gpm} \cdot \mathrm{hr}^{-1}\right)$ [1]. However, these measurements suffer from an accuracy limitation caused by humidity variation due to temperature change, vapor condensation inside CT, and are unable to adequately detect sufficiently small leaks. Recently, several small leak accidents have been reported in Korean nuclear power 
plants, and are seen as a risk that could potentially lead to a high-level accident. For example, in March 2017, 306 liters of leakage occurred at Kori 4 due to a long detection time (more than 12 hours). To increase nuclear power plant safety, a real-time and direct detection system for small leaks with a detection limit below that of existing systems, e.g. $0.5 \mathrm{gpm} \cdot \mathrm{hr}^{-1}$, is required.

In this study, a small-size beta detector, which can be installed inside the reactor CT building and detect small leaks directly, was suggested. The target radionuclide for detection was selected based on an evaluation of data ${ }^{1)}$ from APR1400 RCS [2]. The designs of the detector window and the shielding were performed using $\mathrm{MCNPX}^{2)}$ code and the feasibility of the beta detector was discussed.

\section{Materials and Methods}

\section{Determination of target nuclide}

Radiation from radionuclides in the RCS was analyzed to select a target nuclide for leak detection inside the CT, based on the radionuclide evaluation data from APR1400 [2]. The data was evaluated under the assumption of normal operating conditions with a core power of 3,983 MWt. First, the nuclides emitting gamma rays were analyzed. This analysis showed that the radioactive concentration of ${ }^{16} \mathrm{~N}$ was $93 \%$ of total radioactive concentration inside the RCS and that in the case of gamma rays, the $6.1 \mathrm{MeV}$ and $7.1 \mathrm{MeV}$ gamma rays emitted by ${ }^{16} \mathrm{~N}$ were at $90 \%$ and $6.2 \%$ respectively, accounting for about $96 \%$ of the total number of gamma rays. Be- cause these high energy gamma rays have a high penetrating power, a significant gamma-ray background signal is expected in any gamma-ray detector installed near the RCS elements in the reactor CT. Therefore, it was determined that for detecting leakages a beta particle detector, which is not affected by the high gamma-ray background, would be suitable. Following this decision, an analysis of the beta-emitting nuclides in the RCS was also performed. Figure 1 shows the energy $\left(E_{\beta}\right)$ and amount of beta radiation emitted by the radiation sources inside the RCS during normal operation. Here $\mathrm{E}_{\beta}$ refers to the maximum energy in a continuous spectrum of beta particles. Among the beta particles emitted by RCS radionuclides during normal operation, ${ }^{16} \mathrm{~N}$ was the most significant contributor, accounting for $97 \%$ of the total activity, which was 34 times higher than the second highest activity of ${ }^{85} \mathrm{Kr}$. By energy, the $10.42 \mathrm{MeV}\left(\mathrm{E}_{\beta}\right)$ beta from ${ }^{16} \mathrm{~N}$ was the highest, twice as much energy as the second highest $\mathrm{E}_{\beta}$ from ${ }^{88} \mathrm{Rb}$. Nuclide analysis indicated that the beta particles from ${ }^{16} \mathrm{~N}$ accounted for $96 \%$ of all beta particles and were responsible for an isolated high-energy peak, so ${ }^{16} \mathrm{~N}$ was selected as the target nuclide because its detection would be relatively easy with proper application of signal processing.

\section{Beta/gamma spectrum from RCS radionuclides}

The pulse height caused by RCS beta particles was evaluated using Monte Carlo N-Particle Transport Code Systemextended version 2.7.0 (MCNPX, Los Alamos national lab, Los Alamos, NM). It was assumed that the nuclides were leaking from the RCS and moving to the location of the sili-

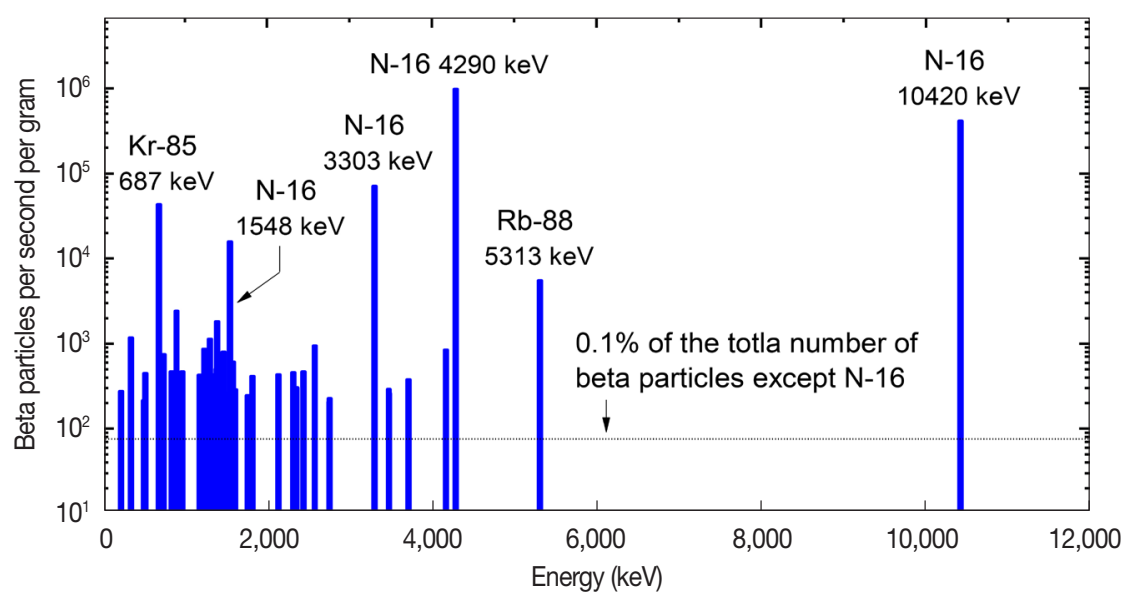

Fig. 1. Energy distribution of beta particles from RCS nuclides during normal operation.

1) S.Y.F. Chu, L.P. Ekström, R.B. Firestone, The Lund/LBNL Nuclear Data Search, 1999; http://nucleardata.nuclear.lu.se/

2) D.B. Pelowitz ed., MCNPX User's Manual Version 2.7.0, LA-CP-11-00438, Los Alamos National Laboratory, 2011. 

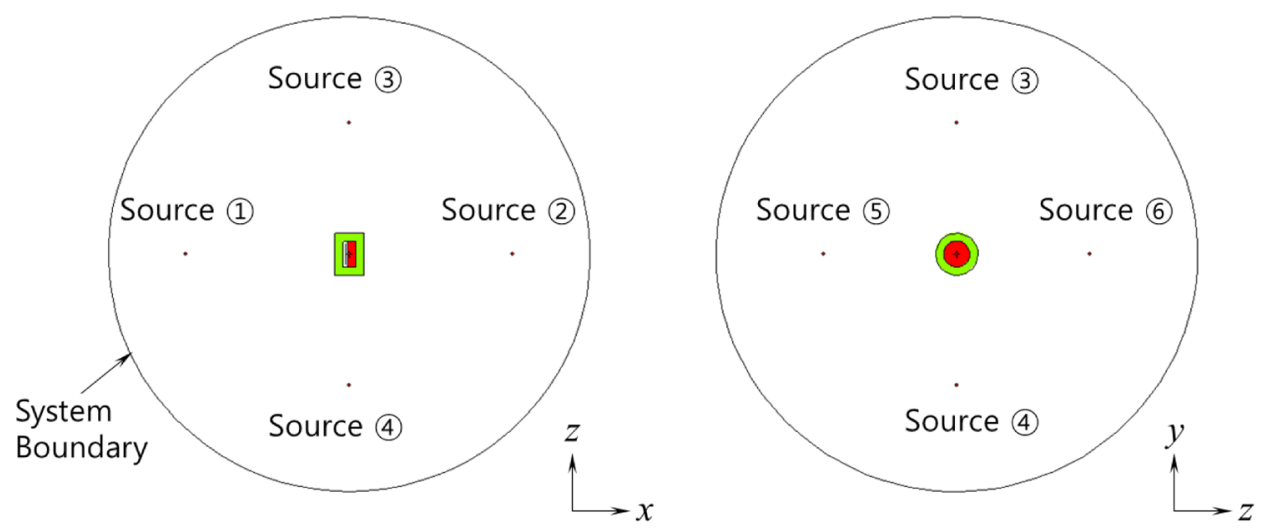

Fig. 2. Simulated silicon detector and gamma ray source positions (by Visual Editor). The detector is located at the center of the circle (system boundary). The sources were 6 isometric point sources located $30 \mathrm{~cm}$ away from the detector.

con beta detector at a sufficiently high speed that any radioactive decay was negligible. The source (beta particles from RCS nuclides) was modelled as a point source, and a pulse height tally (F8 tally) was used. The detector geometry was determined based on the specifications of the ULTRA IonImplanted Detector ${ }^{3)}$ (BU-035-2000-500, Ortec, Oak Ridge, $\mathrm{TN})$. Active area and depletion depth of the silicon were 20 $\mathrm{cm}^{2}$ and $500 \mu \mathrm{m}$, respectively. Mono-energetic $\left(\mathrm{E}_{\beta} / 3\right)$ beta particles were assumed. In case of the gamma-ray source, only 6.1 MeV and 7.1 MeV gamma rays from ${ }^{16} \mathrm{~N}$ were considered because they constitute the dominant gamma-ray background inside the CT.

\section{Detector window design and sensitivity estimation}

Polymethyl methacrylcate (PMMA), aluminum and beryllium, which are commonly used for beta windows, were evaluated as window materials in the simulation. Beta counts were calculated depending on window thickness and compared using pulse height tally. In addition, the detection sensitivity of the silicon detector was roughly estimated by comparing the beta signal of the silicon detector with the gamma signal of a NLM100 BGO detector ${ }^{4}$, which has a detection sensitivity of $5 \times 10^{-7} \mu \mathrm{Ci} \cdot \mathrm{cc}^{-1}$. NLM100 BGO detectors are currently used in nuclear power plants as Steam Generator Leakage rate Monitors (SGLM) to monitor leakage between primary and secondary systems, and are used to detect ${ }^{16} \mathrm{~N}$, the previously specified target nuclide. Since the output signal of the detector is generally proportional to the energy deposited inside the sensor, F6 tally was used to calculate the

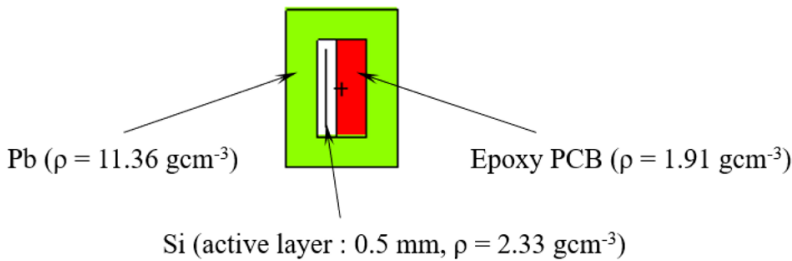

Fig. 3. Detector geometry including lead shielding (by Visual Editor).

energy deposition in each sensor's active volume. The active volume of the NLM100 was 2 "(dia.) × 2"(thickness).

\section{Shielding design}

There is a high amount of background radiation inside the reactor CT where the detector will be located. Especially high energy (6-7 MeV) gamma rays could contribute to noise and damage the sensor or sensitive electronic parts such as the preamplifier. Therefore, gamma-ray shielding was added to the detector and its performance evaluated. Lead was chosen as the material, as is common for high-energy gammaray shielding. It was assumed that the detector was located at the annular space inside of the innermost CT wall (10 $\mathrm{mSv} \cdot \mathrm{hr}^{-1}$ dose rate), and that the energy distribution of ambient gamma rays was same as inside the RCS. The simulation was performed using MCNPX and Figure 2 shows the gamma ray source positions while Figure 3 illustrates the detector geometry and shielding. There would be a small hole in the lead shield for air sampling in actual use, but no hole was considered in this study, because the details of the sampling system were undetermined.

\footnotetext{
3) ULTRA and ULTRA AS Ion-Implanted-Silicon Charged-Particle Detectors, ORTEC, 2017.

4) Model NLM100 Main Steam Line and ${ }^{16} \mathrm{~N}$ Steam Generator Leakage, MIRION TECHNOLOGIES, 2017.
} 

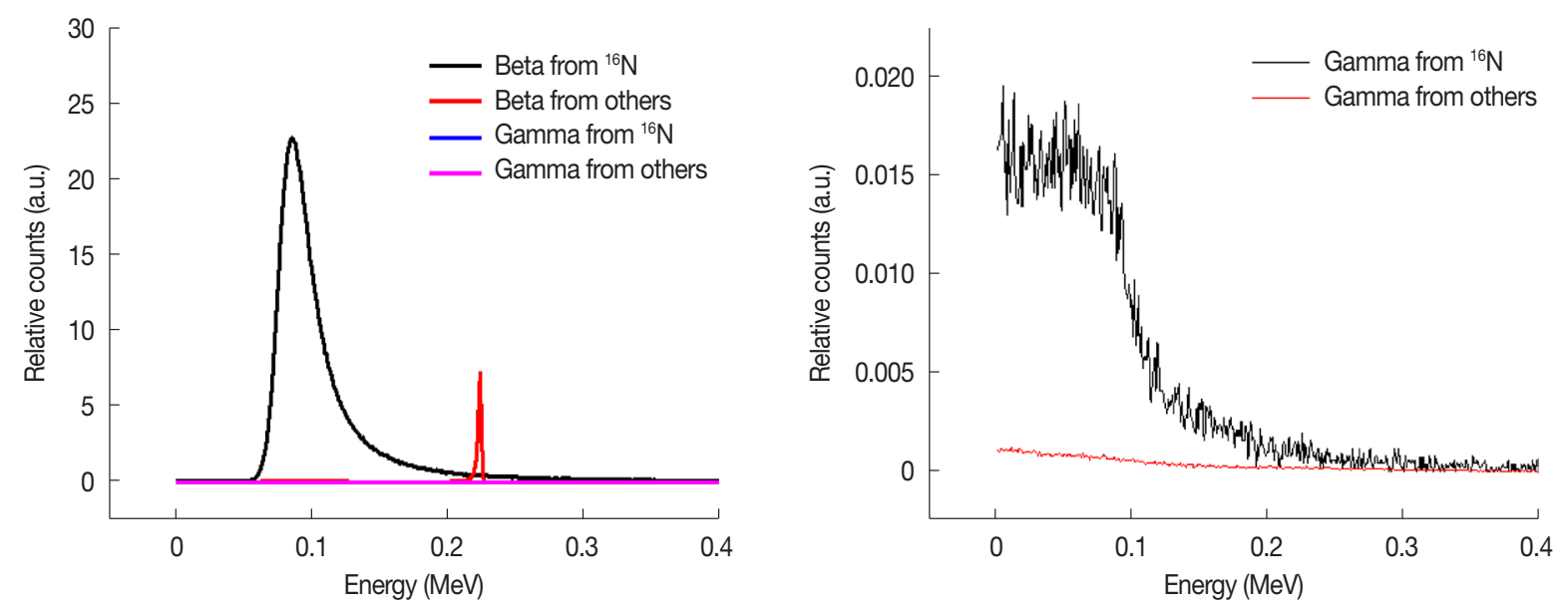

Fig. 4. Beta and gamma-ray spectra of ${ }^{16} \mathrm{~N}$ and other nuclides obtained through MCNPX simulation.

\section{Results and Discussion}

Figure 4 shows the beta and gamma pulse height spectra. In the figure, two beta peaks are clearly visible. The first peak near $0.1 \mathrm{MeV}$ originated from ${ }^{16} \mathrm{~N}$ beta particles while the other peak at $0.22 \mathrm{MeV}$ was due to low energy beta emitters such as ${ }^{85} \mathrm{Kr},{ }^{87} \mathrm{Kr},{ }^{137} \mathrm{Xe},{ }^{88} \mathrm{Rb}$, and ${ }^{84} \mathrm{Br}$. The reason why these lower energy beta particles create a peak in a higher energy region is that the electronic stopping power decreases against the energy of charged particles. Note that the range of beta particles from ${ }^{16} \mathrm{~N}$ is longer than the depletion region of silicon detector; hence, only a portion of the beta energy is deposited in the detector. The $0.22 \mathrm{MeV}$ peak has to be considered an unwanted signal for RCS leak quantification. Accordingly, the detector window to obtain only the signal from only ${ }^{16} \mathrm{~N}$ beta particles was designed. Since the evaluated gamma counts were several orders of magnitude below the beta counts, they appear to be negligible when processing the beta signal.

Figure 5 shows the beta particle counts as functions of the thickness of the various window materials. The counts from RCS radionuclides other than ${ }^{16} \mathrm{~N}$ decreased by $90 \%$ at 0.4 , 0.25 , and $0.4 \mathrm{~mm}$ thickness for beryllium, aluminum, and PMMA respectively, whereas the ${ }^{16} \mathrm{~N}$ counts were nearly constant. In case of PMMA, a thickness of $0.4 \mathrm{~mm}$ was considered too weak, mechanically. Aluminum is a relatively high-Z material which causes Bremsstrahlung X-rays. Accordingly, it was determined that beryllium was the most suitable window material for the beta detector despite its relatively high cost.

Figure 6 shows the beta energy deposited inside the detector depending on the thickness of the beryllium window.
The energy deposition increases up to $0.295 \mathrm{MeV}$ at $1.7 \mathrm{~mm}$ thickness and decreases thereafter due to a decrease of ${ }^{16} \mathrm{~N}$ beta transmission. Consequently, in terms of detection efficiency, the beryllium window thickness ideally should be between $0.4 \mathrm{~mm}$ and $1.7 \mathrm{~mm}$.

Meanwhile, average energy deposited inside the NLM100 BGO detector by ${ }^{16} \mathrm{~N}$ gamma-rays was calculated to be 4.219 $\mathrm{MeV}$. The value is 14.3 times greater than the energy deposited inside the silicon detector by ${ }^{16} \mathrm{~N}$ beta particles $(0.295$ $\mathrm{MeV}$ ). The deposited energy is proportional to the output signal, which is inversely proportional to the sensitivity of detector. Based on that, detection sensitivity of the silicon beta detector was estimated at $5.17 \times 10^{-6} \mu \mathrm{Ci} \cdot \mathrm{cc}^{-1}$, which is 14.3 times greater than that of NLM100 BGO detector.

Figure 7 shows the cumulative dose to the silicon detector as a function of lead shielding thickness. It was assumed that the detector was exposed to an environment of $10 \mathrm{mSv} \cdot \mathrm{hr}^{-1}$ over a duration of 60 years, which is the planned operation period of APR1400. In the figure, the cumulative dose at only $3 \mathrm{~cm}$ lead thickness is $5.91 \mathrm{kGy}$ which is lower than the reported radiation tolerance of a typical silicon detector at 8.77 kGy [3]. The mass of the detector system could be kept below $15 \mathrm{~kg}$. In contrast, if the NLM100 BGO detector were to be used inside the reactor $\mathrm{CT}$ for ${ }^{16} \mathrm{~N}$ leakage detection, it is unavoidable to use massive shielding material for background $\left({ }^{16} \mathrm{~N}\right.$ gamma) reduction. The design criterion of the annular space is 1,000 times higher than that of the outside of CT wall. Therefore, at least $15 \mathrm{~cm}$ of additional lead shielding would be needed for sufficient background reduction. 

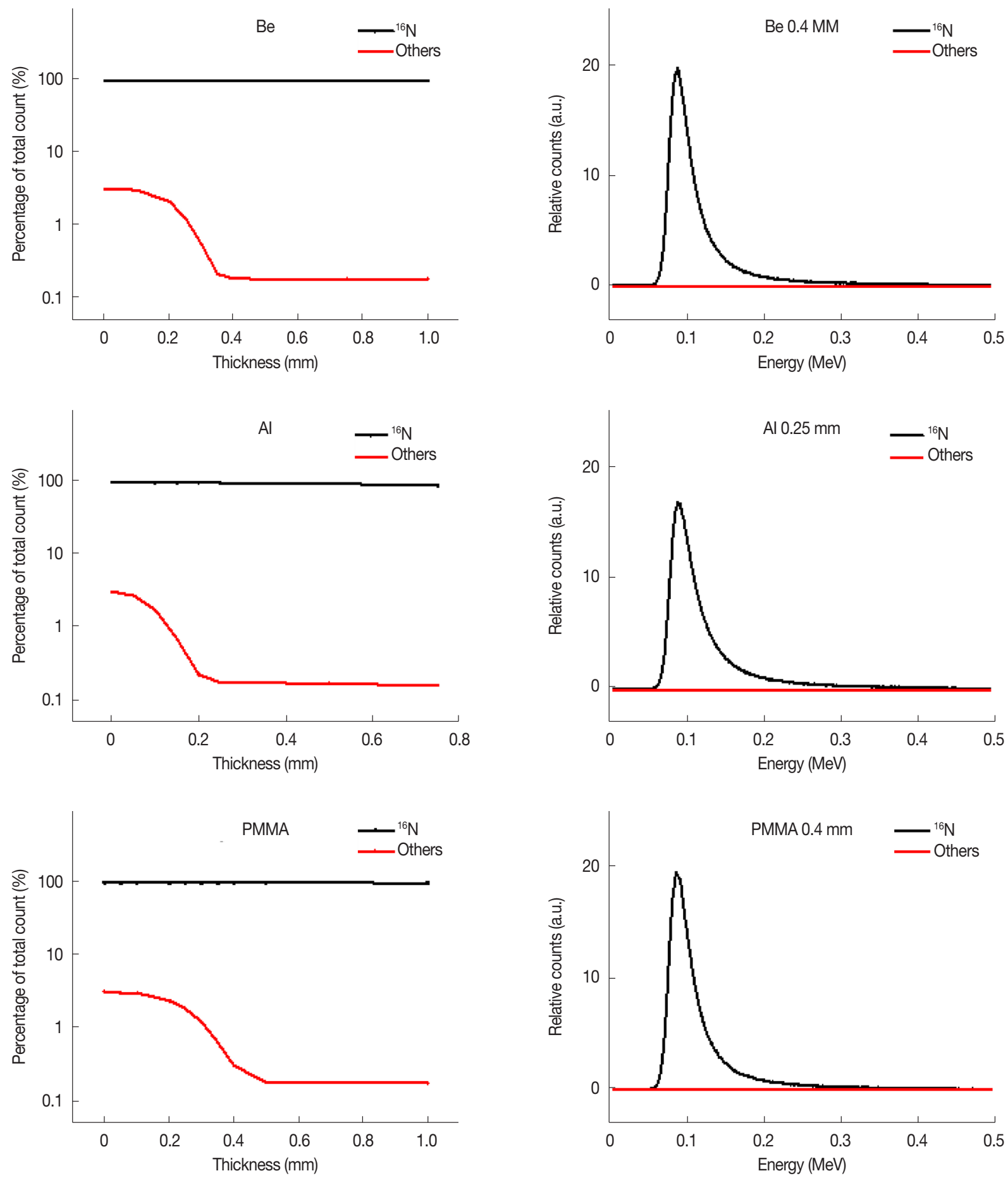

Fig. 5. Percentage of total count and beta spectrum of ${ }^{16} \mathrm{~N}$ and other RCS radionuclides as functions of window thickness and material.

\section{Conclusion}

In this study a small leakage detection system for use inside the reactor CT building was designed and evaluated using MCNPX. Its sensitivity of $5.172 \times 10^{-6} \mu \mathrm{Ci} \cdot \mathrm{cc}^{-1}$ was determined after applying a $1.7 \mathrm{~mm}$ beryllium window to effec- tively detect the beta particle signal of the ${ }^{16} \mathrm{~N}$ target nuclide. Lead shielding was added for installation of the beta detector inside the reactor $\mathrm{CT}$, and based on the cumulative dose over 60 years which is the design life span of the APR1400, it could be shown that a shielding thickness of $3 \mathrm{~cm}$ was sufficient to maintain the integrity of the detector. This is a very small 


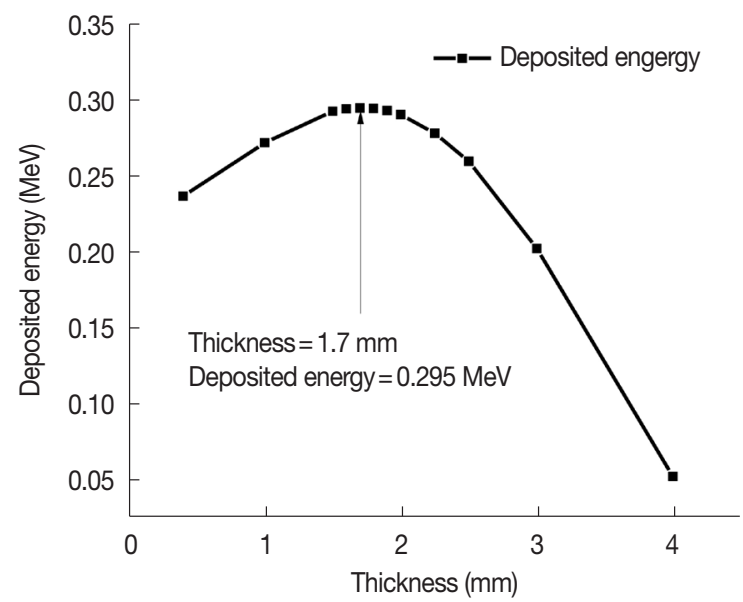

Fig. 6. Energy deposited inside the silicon detector as a function of window thickness.

amount compared to the shielding required to install a gamma detector inside reactor CT. Therefore, this beta detector can be considered a suitable choice for a compact, essential item for installation inside reactor CT with a small spatial margin. However, other beta detectors such as CZT-based ones with relatively high heat resistance are also under consideration as thermal damage to the silicon detector may exceed its heat resistance, depending on the exact installation location. In the near future, it is expected that more precise simulations can be performed by applying new data such as the actual concentration of nuclides inside the reactor CT, more detailed structure of the specific detectors and their installation location, which will be used to optimize the detector design.

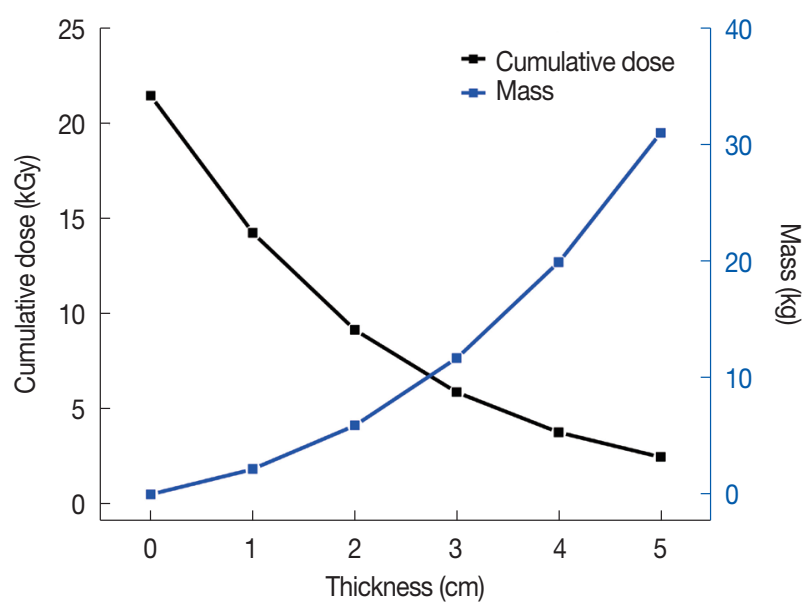

Fig. 7. Cumulative dose to the silicon detector after 60 years of exposure.

\section{Acknowledgement}

This work was supported by the Korea Institute of Energy Technology Evaluation and Planning (KETEP) grant funded by the Korea government (MOTIE) (20181510102340, Development of a real-time detection system for unidentified RCS leakage less than $0.5 \mathrm{gpm})$.

\section{References}

1. U.S. Nuclear Regulatory Commission. Guidance on monitoring and responding to reactor coolant system leakage. Regulatory Guide 1.45, Rev. 1. 2008;5-6.

2. Korea Hydro \& Nuclear power Co., Ltd. APR1400 design control document TIER2. Chapter 11 Radioactive Waste Management. APR1400-K-X-FS-14002-NP, 2014;11.1.27-11.1.28.

3. Knoll GF. Radiation detection and measurement. 4th Ed. New York, NY. John Wiley \& Sons Inc. 2010;398-399. 